\title{
Spatial and Temporal Continuity of Kangaroo Rat Populations Shown by Sequencing Mitochondrial DNA from Museum Specimens
}

\author{
W. Kelley Thomas, Svante Pääbo, Francis X. Villablanca, and Allan C. Wilson
}

Summary. The advent of direct sequencing via the polymerase chain reaction (PCR) has opened up the possibility of molecular studies on museum specimens. Here we analyze genetic variation in populations over time by applying PCR to DNA extracted from museum specimens sampled from populations of one species over the last 78 years. Included in this study were 43 museum specimens of the Panamint kangaroo rat Dipodomys panamintinus from localities representing each of three geographically distinct subspecies. These specimens were originally collected and prepared as dried skins in 1911,1917 , or 1937. For each specimen, a 225bp segment of the mitochondrial genome was sequenced. These mitochondrial DNA sequences were compared to those of 63 specimens collected at the same localities in 1988. The three subspecies were nearly completely distinct. Only 2 of the 106 individuals shared mitochondrial types between subspecies. For all three localities, the diversity levels were maintained between the two temporal samples. The concordance observed between the two temporally separate phylogenies supports the use of museum specimens for phylogenetic inference. This study demonstrates the accuracy and routine nature of the use of museum specimens in the analysis of mitochondrial sequence variation in natural populations and, importantly, that a temporal aspect can now be added to such studies. region - tRNA genes - Population dynamics Population tree - Molecular trees

\section{Introduction}

Over the past 10 years, mitochondrial DNA (mtDNA) has been a productive source of information about genetic variation at and below the species level (for reviews, see Wilson et al. 1985; Harrison 1988). However, because these studies have been restricted to the analysis of present-day populations, they represent a static view of the historic processes that shape the genetic variation detected in contemporary populations. Due to recent technical advances brought about by the polymerase chain reaction (PCR) (Kocher et al. 1989; Pääbo et al. 1989; White et al. 1989), and because for some species samples of populations were collected many decades ago and preserved as museum study specimens, it is now possible to overcome these shortcomings and compare the genetic variation in zoological and archaeological collections with that in populations living today.

Among the vertebrates preserved in museums, the rodents of western North America stand out in the extent of their collections that go back to the early decades of this century. This is especially so for the kangaroo rats (Dipodomys), a North American endemic group (family Heteromyidae) of 20 24 species that inhabit deserts and other arid habitats. Our study utilizes multiple skins available from populations of the Panamint kangaroo rat, Dipodomys panamintinus, which consists of five subspecies that occupy five nonoverlapping regions in California and Nevada (Fig. 1). 


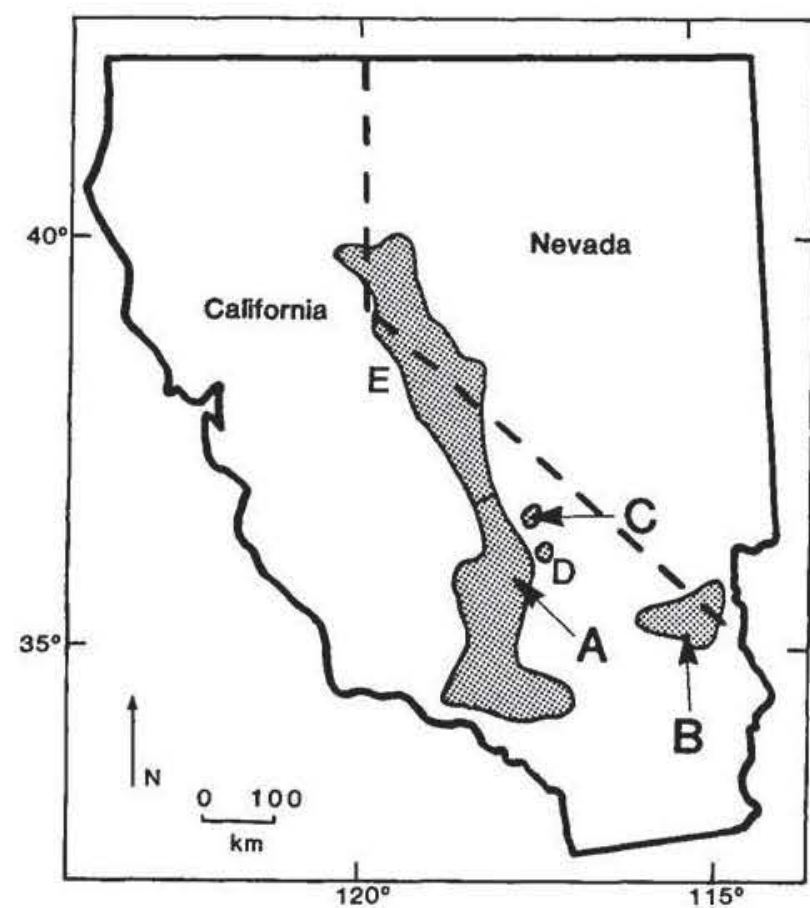

Fig. 1. Geographic ranges occupied by five subspecies (A-E) of Dipodomys panamintinus as given by Hall (1981). Arrows mark the three localities-A with $D$. p. mohavensis, B with $D$. p. caudatus, and C with D. p. panamintinus - where samples of subspecies were collected. The exact localities sampled are described further in the Materials and Methods.

The three subspecies examined here, A, B, and $\mathrm{C}$, include populations occurring in stable undisturbed habitats that have experienced no known sources of population reduction between the sampling dates. Based on the size of the geographic range (Hall 1981), the subspecies sampled with the largest population size (Table 1) is A (Dipodomys panamintinus mohavensis). The second subspecies, B (Dipodomys panamintinus caudatus), has a smaller range and is geographically the most isolated of all the subspecies, whereas the third subspecies sampled, C (Dipodomys panamintinus panamintinus), has a very restricted range and the populations sampled have relatively low densities.

Through the analysis of variation in the mtDNA sequences of these kangaroo rats, we investigate the evolutionary history of their populations in two ways. One way is through estimates of genetic diversity and levels of pairwise sequence difference that are indicators of population size. By sampling each population at two time points, we directly investigate the maintenance of diversity in these natural populations. In addition, information on biogeographic substructuring and potential migration events during the evolution of this species is derived from the phylogenetic relationships of the individuals in these populations. Genetic continuity and timing of potential immigration events in these populations are
Table 1. Rough estimates of population sizes for three subspecies of Panamint kangaroo rats, Dipodomys panamintinus

\begin{tabular}{lclc}
\hline & & $\begin{array}{l}\text { Popula- } \\
\text { tion } \\
\text { density } \\
\text { (number/ } \\
\left.\mathrm{km}^{2}\right)\end{array}$ & $\begin{array}{l}\text { Approximate } \\
\text { population } \\
\text { size } \\
\text { (thousands) }\end{array}$ \\
\hline A, mohavensis & 20,000 & 295 & $1060-5900$ \\
B, caudatus & 6000 & 105 & $318-1770$ \\
C, panamintinus & 500 & 53 & $27-148$ \\
\hline
\end{tabular}

Range sizes were estimated from Hall (1981). Population densities are based on trapping efficiencies per night at each locality. Maximum and minimum population sizes are based on the range of densities found at all three localities

assessed by comparisons of lineages between the museum specimens and modern samples.

\section{Materials and Methods}

Sampling Localities. Contemporary collections were made from August to October 1988 at the same localities determined from review of the original collectors' field notes.' Fourteen museum skins from 1911 and 20 modern specimens of D. p. mohavensis came from the western slope of Walker Pass, Kern County, California $(1400 \mathrm{~m})$. The D. p. caudatus samples included $21 \mathrm{mu}$ seum skins from 1937 and 19 modern specimens from $9.7 \mathrm{~km}$ south of Granite Well, Providence Mountains, San Bernardino County, California (1158 m). Fourteen museum specimens from 1917 and 24 modern D. p. panamintinus individuals were sampled from 3.0 to $5.0 \mathrm{~km}$ northeast of Jackass Spring, Panamint Mountains, Inyo County, California (2079 m). See the Appendix for specimen numbers of these 112 animals. Samples of $D$. heermanni [Museum of Vertebrate Zoology (MVZ), specimen FC2894] and $D$. californicus (MVZ-FC2602) were taken from frozen liver specimens. All modern specimens were collected using live-trapping techniques for small mammals, with linearly arranged traplines and trap stations at fixed intervals occupying a total area of approximately $1 \mathrm{~km}^{2}$. Museum specimens were snap-trapped.

DNA Extractions. A half gram of liver from modern specimens or $1-3 \mathrm{~mm}^{2}$ of dried skin tissue from museum specimens was digested in $8 \mathrm{ml}$ of $10 \mathrm{mM}$ Tris- $\mathrm{HCl}$ ( $\mathrm{pH} 8.0$ ), 2 mM ethylenediamine tetraacetate (EDTA), $10 \mathrm{mM} \mathrm{NaCl}, 1 \%$ sodium dodecyl sulfate, $10 \mathrm{mg} / \mathrm{ml}$ of dithiothreitol, and $0.5 \mathrm{mg} / \mathrm{ml}$ proteinase $\mathrm{K}$ at $37^{\circ} \mathrm{C}$ with constant gentle mixing for approximately $20 \mathrm{~h}$. The resulting solution was extracted twice with phenol ( $\mathrm{pH} \mathrm{8.0)}$ and once with chloroform/isoamyl alcohol $(24: 1)$. For museum specimens approximately $10 \%$ of the extract was then concentrated and desalted on a Centricon 30 microconcentrator (Amicon). In the case of fresh liver, total nucleic acids were recovered from the extract by the addition of 2.5 volumes of ethanol and centrifugation.

Amplifications and Sequencing. The PCR was performed in $50-\mu \mathrm{l}$ reactions containing $67 \mathrm{mM}$ Tris- $\mathrm{HCl}(\mathrm{pH} 8.8), 2 \mathrm{mM}$ $\mathrm{MgCl}_{2}, 10 \mathrm{mM} \beta$-mercaptoethanol, $250 \mu \mathrm{M}$ each of dGTP, dATP,

' Original field notes are located at the Museum of Vertebrate Zoology, University of California at Berkeley. Copies of field notes are available from F.X. Villablanca 
Primer 1

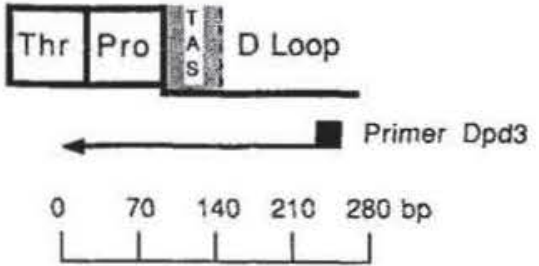

Fig. 2. Amplification scheme for a specific segment of $D$. panamintinus mtDNA. Primer A is the versatile L15926 primer of Kocher et al. (1989) with sequence 5'-TCAAAGCTTACACCAGTCTTGTAAACC-3'. Primer B, 5'-GTACGTGTCACGGAAAATCT - $3^{\prime}$, is specific for the control region of kangaroo rat mtDNAs. Thr and Pro denote the tRNA genes for threonine and proline, TAS refers to the termination-associated sequence (Brown et al. 1986), and D loop indicates the displacement loop.

dTTP, and dCTP, $2 \mu \mathrm{g} / \mathrm{ml}$ bovine serum albumin (Sigma, fraction V), and 12.5 units of Thermus aquaticus DNA polymerase (Perkin Elmer-Cetus). Thermal cycling was done in a programmable heating block (Perkin Elmer-Cetus).

Initial amplifications of the entire major noncoding region (control region, including the D loop) of frozen specimens of $D$. panamintinus and $D$. heermanni employed the versatile primers L15926 and H651 described by Kocher et al. (1989). Subsequent amplifications were performed with L15926 and an internal primer designated Dpd3 (Fig. 2). Dpd3 was used in order to reduce the size of the fragment being amplified, because that increases the efficiency of amplifications from old templates (Pääbo et al. 1988; Păäbo 1989). Amplifications with L1 5926 and Dpd3 were carried out by denaturation at $92^{\circ} \mathrm{C}$ for $30 \mathrm{sec}$, annealing at $50^{\circ} \mathrm{C}$ for 1 $\mathrm{min}$, and extension at $72^{\circ} \mathrm{C}$ for $1 \mathrm{~min}$. Amplifications from museum specimens required 40 cycles, whereas modern DNA extracts required 30 cycles. Extraction controls, where no museum skin or liver was included during the extraction procedure, as well as amplification controls, in which water was added to the reaction in place of tissue extract, were performed throughout. Such controls are imperative to ensure that the sequences being amplified are from the specimens being examined and not due to laboratory contamination (Pääbo 1990).

Amplification products were resolved by electrophoresis in a $4 \%$ NuSieve agarose gel in Tris-acetate buffer and stained with thidium bromide to visualize the DNA. One to $2 \mu \mathrm{l}$ of each of the isolated double-stranded bands were used as templates for amplifications during which templates for sequencing were generated by the unbalanced priming method (Gyllensten and Erlich 1988). Thirty cycles under the same conditions as above were performed, with the exception that one of the primers was reduced 100 -fold in concentration. After centrifugal dialysis on Centricon 30 microconcentrators, $7 \mu$ l of the retentate was used for sequencing using the dideoxynucleotide chain termination method and Sequenase enzyme (United States Biochemical). The products of the sequencing reactions were resolved in $6 \%$ polyacrylamide $7 \mathrm{M}$ urea wedge gels and autoradiographed.

Sequence Analysis. Mean pairwise differences between individuals were calculated as the percentage of positions where differences were observed. For comparisons of individuals from one population with those of another population, Eq. (1) was used.

$$
\mathrm{D}=\mathrm{D}_{\mathrm{Xr}}-0.5\left(\mathrm{D}_{\mathrm{X}}+\mathrm{D}_{\mathrm{Y}}\right)
$$

Where $D$ is the corrected mean difference between populations $X$ and $Y, D_{X Y}$ is the observed mean difference between the two populations, $\mathrm{D}_{X}$ is the mean difference within population $\mathrm{X}$, and $D_{Y}$ is the corresponding value for population $Y(\mathrm{cf}$. Wilson et al.

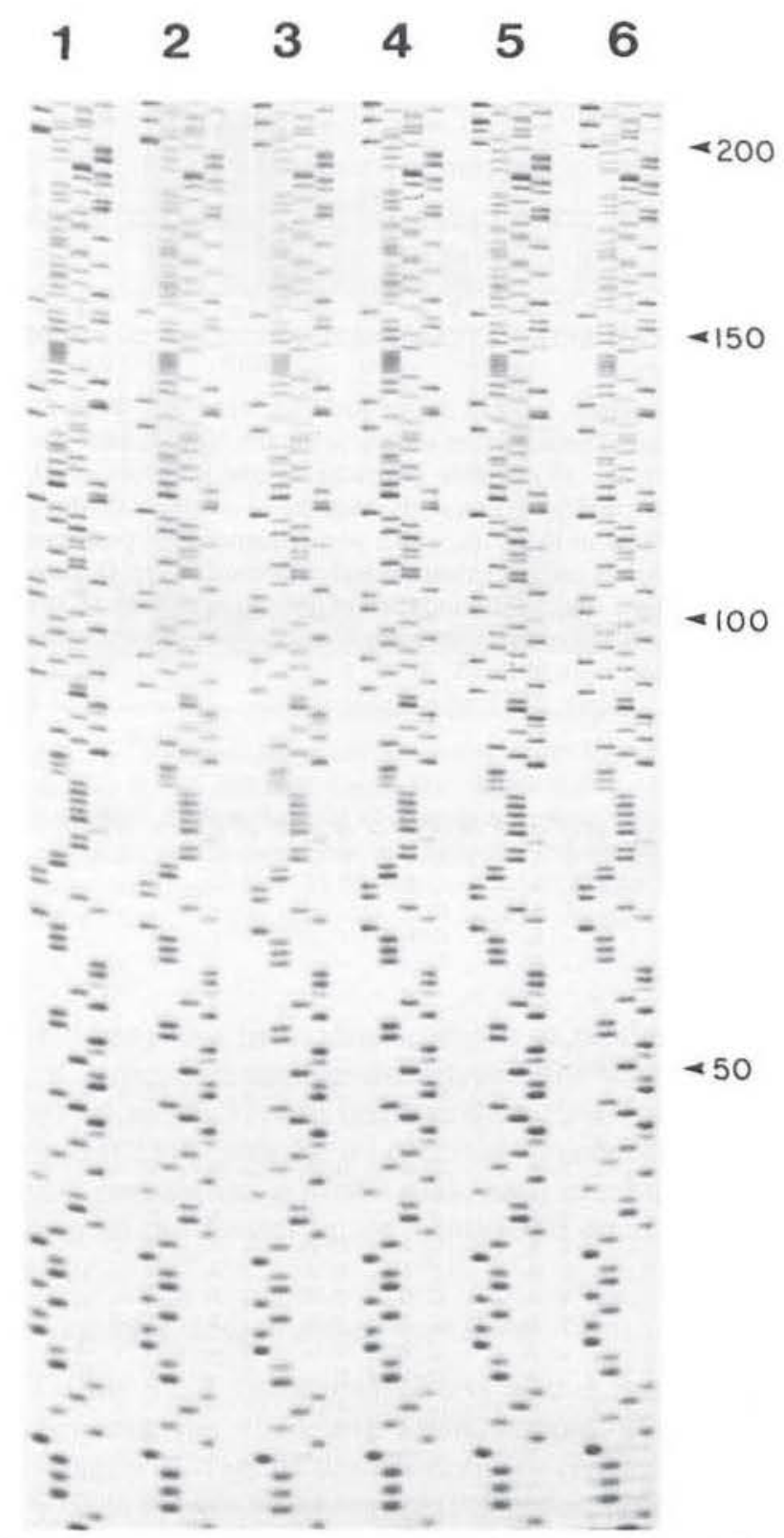

Fig. 3. Sequencing gel demonstrating the quality of the results obtainable from museum specimens. The six sequences are from specimens collected at locality B in 1937, and the sequences from left to right correspond to mtDNA types B4, B4, B1, B7, B6, and B2. Nucleotide positions are numbered as in Fig. 4.

1985; Cann et al. 1987). The genetic diversity (h) was calculated as in Nei and Tajima (1981). Sequences were aligned with the aid of ESEE (Cabot and Beckenbach 1989). The genealogical relationships among the mtDNA types were obtained by parsimony analysis using PAUP (Swofford 1989).

\section{Results}

\section{DNA Sequence Variation}

For each of the 63 modern and 49 museum specimens (of $D$. panamintinus) extracted and amplified, a single double-stranded product was visible after 


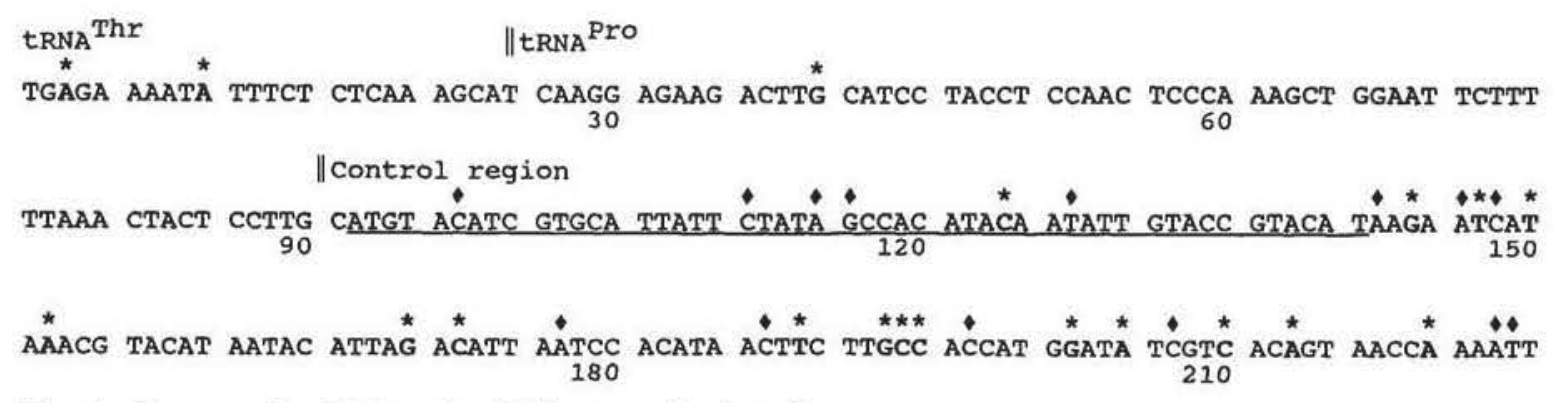

Fig. 4. Sequence for $225 \mathrm{bp}$ of mtDNA, type $A 1$, from $D$. panamintinus. The sequence shown is for the light strand. Asterisks mark the 19 variable positions among 23 types of $D$. panamintinus mtDNA; diamonds mark the 14 positions at which the $D$. californicus mtDNA, which was sequenced for positions 88-225, exhibits unique substitutional differences from $D$. panamintinus (see Fig. 5). Boundaries of the three regions of the genome are indicated; the termination-associated sequence of the control region is underlined.

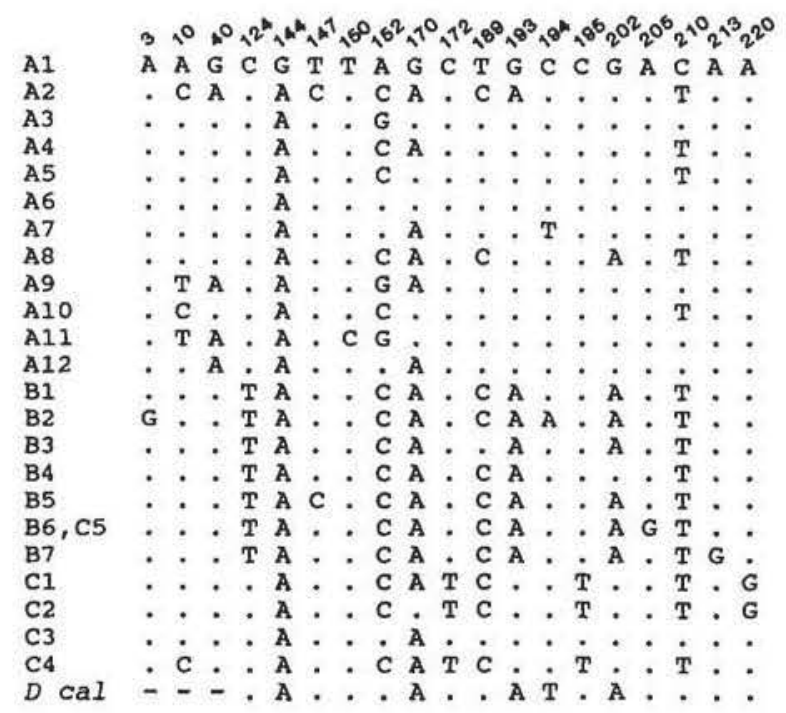

Fig. 5. Nineteen variable positions among the $106 \mathrm{D}$. panamintinus mtDNAs sequenced. The nucleotide at each variable position in type $\mathrm{A} 1$ is given. In all other types the nucleotide is given where different from Al, with identity being indicated by a dot. For $D$. californicus the sequence at positions variable in D. panamintinus is shown. Dipodomys californicus differs at 14 additional sites (Fig. 4) and has a single inserted nucleotide that is not found in any D. panamintinus mtDNA.

30 or 40 cycles of PCR. Typical sequencing reactions from modern and museum tissues gave single unambiguous sequences (Fig. 3). For each specimen, a total of $225 \mathrm{bp}$ of sequence was determined. The sequence for this region (Fig. 4) appears, by inference from sequence similarity with mouse and other vertebrate mtDNAs (Bibb et al. 1981; Roe et al. 1985), to include three functionally distinct regions: (1) a partial sequence for the tRNA ${ }^{\text {Thr }}$ gene, (2) the complete sequence of the tRNA ${ }^{\text {Pro }}$ gene, and (3) 135 bp of noncoding sequence in the putative control
Table 2. Nonrandom distribution of variables sites in a segment of D. panamintinus mtDNA

\begin{tabular}{lrcc}
\hline & \multicolumn{3}{c}{ Variable sites } \\
\cline { 3 - 4 } Region & $\begin{array}{r}\text { Size } \\
(\mathrm{bp})\end{array}$ & $\begin{array}{l}\text { Ob- } \\
\text { served }\end{array}$ & Expected \\
\hline tRNAs & 90 & 3 & 7.6 \\
Termination sequence (TAS) & 50 & 1 & 4.2 \\
Remainder of control region & 85 & 15 & 7.2 \\
Total & 225 & 19 & 19 \\
\hline
\end{tabular}

Regions are defined as in Fig. 4: tRNAs, positions 1-90; termination sequence, positions 92-141; remainder of control region (D loop), positions 91 and 142-225. The expected values assume a random distribution of variable sites. The probability that the observed distribution could occur by chance is less than 0.005 (chi-square $=13.67,2 \mathrm{df}$ )

region (Fig. 2). From position 92 to 141 the sequence has the potential to form a stem-loop structure that is analogous to a region of proposed secondary structure [called the termination-associated sequence (TAS)] implicated in the termination of the D-loop strands in other mammals (Saccone et al. 1985; Brown et al. 1986). By contrast, the sequence from 142 to 225 shows no clear identity to the control region of other vertebrates, which is expected owing to the high rate of evolution of this segment of the control region.

Among $106 \mathrm{D}$. panamintinus individuals, 19 of the 225 positions in the sequence are variable (Figs. 4 and 5). As expected for closely related populations, the variation in these sequences is predominantly due to transitions (Greenberg et al. 1983). Transversions are seen at only three positions $(10,152$, and 194), and each of these positions has experienced two or more changes. No length variation was evident among the mtDNAs of $D$. panamintinus individuals. When comparisons were made of more distantly related control regions from other species of Dipodomys, some length differences were encountered (legend to Fig. 5; W.K. Thomas and F.X. Villablanca, unpublished).

From Fig. 4 it is clear that most of the variation is limited to the $3^{\prime}$ end of the sequence, outside the tRNA genes and the TAS. If the sequence is divided into the three proposed functional domains (i.e., 
Table 3. Mitochondrial DNA genotypes of 106 modern and museum specimens of kangaroo rats from three subspecies

\begin{tabular}{|c|c|c|c|c|c|}
\hline \multirow{2}{*}{$\begin{array}{l}\text { mtDNA } \\
\text { type }\end{array}$} & \multicolumn{2}{|c|}{ Number } & \multirow{2}{*}{$\begin{array}{l}\text { mtDNA } \\
\text { type }\end{array}$} & \multicolumn{2}{|c|}{ Number } \\
\hline & Mod & Mus & & Mod & Mus \\
\hline $\mathrm{Al}$ & 5 & 4 & B1 & 16 & 13 \\
\hline A 2 & 4 & 0 & B2 & 2 & 3 \\
\hline $\mathrm{A} 3$ & 4 & 0 & B3 & 1 & 0 \\
\hline A4 & 3 & 0 & B4 & 0 & 2 \\
\hline As & 2 & 2 & B5 & 0 & 1 \\
\hline A6 & 1 & 0 & B6 & 0 & 1 \\
\hline A7 & 1 & 0 & B7 & 0 & 1 \\
\hline A8 & 0 & 1 & Total & 19 & 21 \\
\hline A9 & 0 & 2 & & & \\
\hline A10 & 0 & 2 & $\mathrm{Cl}$ & 19 & 5 \\
\hline All & 0 & 1 & $\mathrm{C} 2$ & 2 & 0 \\
\hline $\mathrm{A}_{12}$ & 0 & 2 & C3 & 2 & 1 \\
\hline \multirow[t]{3}{*}{ Total } & 20 & 14 & C4 & 1 & 1 \\
\hline & & & $\mathrm{Cs}$ & 0 & 1 \\
\hline & & & Total & 24 & 8 \\
\hline
\end{tabular}

The letters A, B, and C represent the three subspecies. All modern (Mod) specimens were collected in 1988; the museum (Mus) specimens were collected in 1911, 1937, and 1917, respectively, for A, B, and C. The Appendix lists the specific individuals having each type of miDNA

tRNA, TAS, and D loop), the distribution of variable sites among them does not fit with random expectations (Table 2), due to a relative lack of variable sites in the TRNA and TAS region compared to the D loop.

\section{Diversity of mtDNA Types}

Twenty-three mitochondrial genotypes were identified among the 106 individuals analyzed (Fig. 6 and Table 3). Twelve of these types occur in the geographically most widespread subspecies (A), seven in subspecies $B$, and five in the subspecies with the most limited range $(C)$. Only one mitochondrial type (B6, C5) was shared between geographically defined subspecies, and it was uncommon in both subspecies (Table 3).

Pairwise differences among all mitochondrial types are given in Table 4. Up to 12 differences are found between the most divergent types. Estimates of the mean pairwise difference between individuals at each locality were made for each temporal sample. The values range from 0.5 (i.e., $0.22 \%$ ) for the 1988 sample at locality B to 3.9 (i.e., 1.72\%) in the 1988 sample from locality A (Table 5). In addition, comparisons were made between the $\mathrm{A}, \mathrm{B}$, and $\mathrm{C}$ populations. The mean numbers of differences between individuals of different populations were 6.7 for A vs B, 6.4 for A vs C, and 6.2 for B vs C. Thus, they consistently exceed the mean differences found within populations.

Estimates of genetic diversity, or the probability

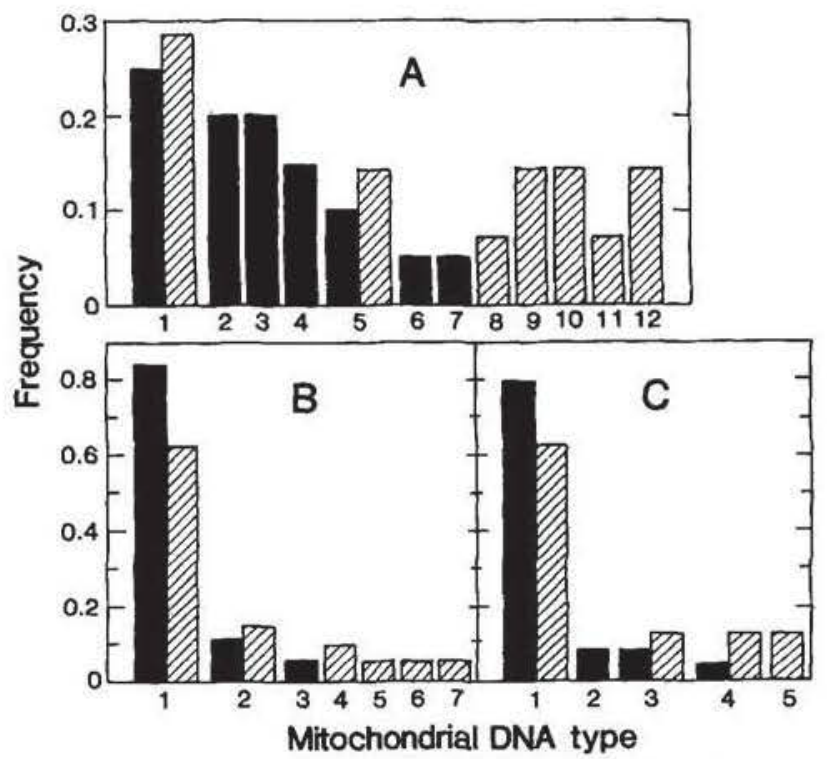

Fig. 6. Frequencies of mitochondrial types found at three localities at two different times. The values shown are computed from the data in Table 3. For each subspecies the solid bars represent collections made in 1988; the striped bars represent collections made in 1911 for subspecies A, 1937 for B, and 1917 for $C$.

that any two individuals chosen at random will be of different mitochondrial types, for the $C$ sample (0.64 and 0.37$)$ are not less than those for B (0.61 and 0.29) (Table 5). By contrast, diversity estimates for population $\mathrm{A}(0.89$ and 0.86$)$ are higher than any of the estimates for localities B and C.

\section{Genotype Maintenance over Time}

Of the 12 A types, only 2 (A1 and A5) are shared between the 1911 and 1988 samples (Fig. 6). At locality B, two of the six lineages (B1 and B2) are shared between the temporal samples. From locality $\mathrm{C}$, with the subspecies having the smallest population, three of the five lineages $(\mathrm{Cl}, \mathrm{C} 3$, and C4) are found in both the 1917 and 1988 samples. For both temporal samples of the B and C populations, one of the shared types is found at a high frequency (62$84 \%$ ), namely, type $\mathrm{B} 1$ in population $\mathrm{B}$ and $\mathrm{Cl}$ in population C (Fig. 6).

\section{Phylogenetic Relationships}

\section{Population Tree}

A UPGMA (unweighted pair-group method using arithmetic averages) tree relating the populations studied was constructed from corrected interpopulation distances, calculated with Eq. (1), which corrects for variation within populations (Fig. 7). The mean pairwise differences between temporal samples (when corrected for variation within each sam- 
Table 4. Pairwise differences among 23 Dipodomys panamintinus mitochondrial genotypes and one from Dipodomys californicus

\begin{tabular}{|c|c|c|c|c|c|c|c|c|c|c|c|c|}
\hline $\begin{array}{l}\text { Genotypes } \\
\text { compared }\end{array}$ & A1 & $\mathrm{A} 2$ & $\mathrm{~A} 3$ & A4 & A5 & A6 & A7 & A8 & A9 & A10 & Al1 & A 12 \\
\hline Al & - & 7 & 2 & 3 & 2 & 1 & 3 & 5 & 4 & 2 & 4 & 3 \\
\hline $\mathrm{A} 2$ & 2 & - & 6 & 4 & 5 & 6 & 6 & 4 & 5 & 5 & 7 & 4 \\
\hline $\mathrm{A} 3$ & 0 & 2 & - & 2 & 1 & 1 & 3 & 4 & 2 & 1 & 2 & 3 \\
\hline A4 & 1 & 1 & 1 & - & 1 & 2 & 2 & 2 & 2 & 1 & 4 & 2 \\
\hline As & 1 & 1 & 1 & 0 & - & 1 & 3 & 3 & 3 & 0 & 3 & 3 \\
\hline A6 6 & 0 & 2 & 0 & 1 & 1 & - & 2 & 4 & 3 & 1 & 3 & 2 \\
\hline A7 & 0 & 2 & 0 & 1 & 1 & 0 & - & 4 & 3 & 3 & 5 & 2 \\
\hline A8 & 1 & 1 & 1 & 0 & 0 & 1 & 1 & - & 4 & 3 & 6 & 4 \\
\hline A9 & 1 & 1 & 1 & 2 & 2 & 1 & 1 & 2 & - & 4 & 2 & 1 \\
\hline $\mathrm{A} 10$ & 2 & 0 & 2 & 1 & 1 & 2 & 2 & 1 & 1 & - & 4 & 3 \\
\hline All & 1 & 1 & 1 & 2 & 2 & 1 & 1 & 2 & 0 & 1 & - & 3 \\
\hline $\mathrm{A} 12$ & 0 & 2 & 0 & 1 & I & 0 & 0 & 1 & 1 & 2 & 1 & - \\
\hline BI & 1 & 1 & 1 & 0 & 0 & 1 & 1 & 0 & 2 & 1 & 2 & 1 \\
\hline B2 & 2 & 2 & 2 & 1 & 1 & 2 & 2 & I & 3 & 2 & 3 & 2 \\
\hline B3 & 1 & 1 & 1 & 0 & 0 & 1 & 1 & 0 & 2 & 1 & 2 & 1 \\
\hline B4 & 1 & 1 & 1 & 0 & 0 & 1 & 1 & 0 & 2 & 1 & 2 & 1 \\
\hline B5 & 1 & 1 & 1 & 0 & 0 & 1 & 1 & 0 & 2 & 1 & 2 & 1 \\
\hline B6 & 1 & 1 & 1 & 0 & 0 & 1 & 1 & 0 & 2 & 1 & 2 & 1 \\
\hline B7 & 1 & 1 & 1 & 0 & 0 & 1 & 1 & 0 & 2 & 1 & 2 & 1 \\
\hline $\mathrm{Cl}$ & 1 & 1 & 1 & 0 & 0 & 1 & 1 & 0 & 2 & 1 & 2 & 1 \\
\hline $\mathrm{C} 2$ & 1 & 1 & 1 & 0 & 0 & 1 & 1 & 0 & 2 & 1 & 2 & 1 \\
\hline C3 & 0 & 2 & 0 & 1 & 1 & 0 & 0 & 1 & 1 & 2 & 1 & 0 \\
\hline $\mathrm{C} 4$ & 2 & 0 & 2 & 1 & 1 & 2 & 2 & 1 & 1 & 0 & 1 & 2 \\
\hline $\mathrm{Cs}$ & 1 & 1 & 1 & 0 & 0 & 1 & 1 & 0 & 2 & 1 & 2 & 1 \\
\hline D. californicus & 8 & 9 & 8 & 9 & 9 & 8 & 8 & 9 & 8 & 9 & 8 & 8 \\
\hline
\end{tabular}

For each pair of sequences, the number of transitions is given above the diagonal and the number of transversions below the diagonal. Boxes highlight intrasubspecific differences. Interspecific comparisons of a $D$. californicus mtDNA with those from $D$. panamintinus are for a subsection of the sequence, positions 88-225. The 14 unique changes (six transitions and eight transversions) in $D$. californicus described in the legend to Fig. 4 have been included in the matrix here

Table 5. Genetic variation in mtDNA of three subspecies of Dipodomys panamintinus

\begin{tabular}{|c|c|c|c|c|c|}
\hline Subspecies & Date & $\begin{array}{l}\text { Number } \\
\text { of indi- } \\
\text { viduals }\end{array}$ & $\begin{array}{l}\text { Number } \\
\text { of mito- } \\
\text { chondrial } \\
\text { genotypes }\end{array}$ & $\begin{array}{l}\text { Mean } \\
\text { pairwise } \\
\text { sequence } \\
\text { differ- } \\
\text { ence }(\%)^{n}\end{array}$ & $\begin{array}{l}\text { Genetic } \\
\text { diver- } \\
\text { sity (h) }\end{array}$ \\
\hline \multirow[t]{3}{*}{ A } & 1911 & 14 & 7 & 1.60 & 0.89 \\
\hline & 1988 & 20 & 7 & 1.72 & 0.86 \\
\hline & Both & 34 & 12 & 1.66 & 0.89 \\
\hline \multirow[t]{3}{*}{ B } & 1937 & 21 & 6 & 0.44 & 0.61 \\
\hline & 1988 & 19 & 3 & 0.22 & 0.29 \\
\hline & Both & 40 & 7 & 0.33 & 0.47 \\
\hline \multirow[t]{3}{*}{ C } & 1917 & 8 & 4 & 1.51 & 0.64 \\
\hline & 1988 & 24 & 4 & 0.56 & 0.37 \\
\hline & Both & 32 & 5 & 0.79 & 0.43 \\
\hline \multirow{3}{*}{$A+B+C$} & Early & 43 & 16 & 2.18 & 0.89 \\
\hline & 1988 & 63 & 14 & 2.16 & 0.84 \\
\hline & Both & 106 & 23 & 2.20 & 0.86 \\
\hline
\end{tabular}

"Between individuals (not between mtDNA types)

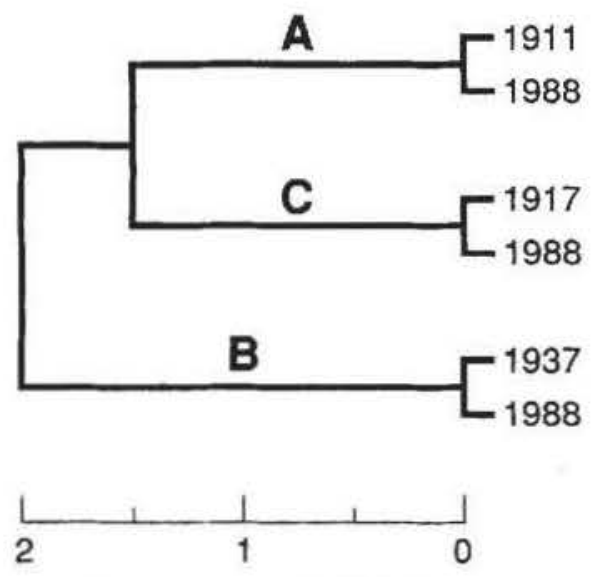

\section{Percent sequence difference}

Fig. 7. Population tree relating the six population samples of kangaroo rats from three localities and two times. Corrected percent differences, $D$, were computed from the values in 1 dble 4 by means of Eq. (1). The tree was built by the UPGMA method and rooted at the midpoint of the greatest interpopulation distance. This root is similar in position to that obtained with $D$. californicus as an outgroup. 
Table 4. Extended

\begin{tabular}{|c|c|c|c|c|c|c|c|c|c|c|c|c|}
\hline B1 & B2 & B3 & B4 & B5 & B6 & B7 & $\mathrm{Cl}$ & $\mathrm{C} 2$ & $\mathrm{C} 3$ & $\mathrm{C} 4$ & C5 & D. californicus \\
\hline 7 & 8 & 6 & 6 & 8 & 8 & 8 & 7 & 6 & 2 & 6 & 8 & 11 \\
\hline 4 & 5 & 5 & 3 & 3 & 5 & 5 & 6 & 7 & 5 & 5 & 5 & 11 \\
\hline 6 & 7 & 5 & 5 & 7 & 7 & 7 & 6 & 5 & 2 & 5 & 7 & 11 \\
\hline 4 & 5 & 3 & 3 & 5 & 5 & 5 & 4 & 5 & 1 & 3 & 5 & 10 \\
\hline 5 & 6 & 4 & 4 & 6 & 6 & 6 & 5 & 4 & 2 & 4 & 6 & 11 \\
\hline 6 & 7 & 5 & 5 & 7 & 7 & 7 & 6 & 5 & 1 & 5 & 7 & 10 \\
\hline 6 & 6 & 5 & 5 & 7 & 7 & 7 & 6 & 7 & 1 & 5 & 7 & 8 \\
\hline 2 & 3 & 3 & 3 & 3 & 3 & 3 & 4 & 5 & 3 & 3 & 3 & 10 \\
\hline 6 & 7 & 5 & 5 & 7 & 7 & 7 & 6 & 7 & 2 & 6 & 7 & 10 \\
\hline 5 & 6 & 4 & 4 & 6 & 6 & 6 & 5 & 4 & 2 & 4 & 6 & 11 \\
\hline 8 & 9 & 7 & 7 & 9 & 9 & 9 & 8 & 7 & 4 & 8 & 9 & 12 \\
\hline 6 & 7 & 5 & 5 & 7 & 7 & 7 & 6 & 7 & 1 & 5 & 7 & 9 \\
\hline- & 1 & 1 & 1 & 1 & 1 & 1 & 6 & 7 & 5 & 5 & 1 & 10 \\
\hline 1 & - & 2 & 2 & 2 & 2 & 2 & 7 & 8 & 6 & 6 & 2 & 9 \\
\hline 0 & 1 & - & 2 & 2 & 2 & 2 & 7 & 8 & 4 & 6 & 2 & 9 \\
\hline 0 & 1 & 0 & - & 2 & 2 & 2 & 5 & 6 & 4 & 4 & 2 & 11 \\
\hline 0 & 1 & 0 & 0 & - & 2 & 2 & 7 & 8 & 6 & 6 & 2 & 11 \\
\hline 0 & 1 & 0 & 0 & 0 & - & 2 & 7 & 8 & 6 & 6 & 0 & 11 \\
\hline 0 & 1 & 0 & 0 & 0 & 0 & - & 7 & 8 & 6 & 6 & 2 & 11 \\
\hline 0 & 1 & 0 & 0 & 0 & 0 & 0 & - & 1 & 5 & 1 & 7 & 14 \\
\hline 0 & 1 & 0 & 0 & 0 & 0 & 0 & 0 & - & 6 & 2 & 8 & 15 \\
\hline 1 & 2 & 1 & 1 & 1 & 1 & 1 & 1 & 1 & - & 4 & 6 & 9 \\
\hline 1 & 2 & 1 & 1 & 1 & 1 & 1 & 1 & 1 & 2 & - & 6 & 13 \\
\hline 0 & 1 & 0 & 0 & 0 & 0 & 0 & 0 & 0 & 1 & 1 & - & 11 \\
\hline 9 & 10 & 9 & 9 & 9 & 9 & 9 & 9 & 9 & 8 & 9 & 9 & - \\
\hline
\end{tabular}

ple) are exceedingly small (i.e., not significantly different from $0.0 \%$ ). By contrast, the mean difference between localities ranged from 1.5 to $2.0 \%$. This result emphasizes how very similar the museum samples are to their modern counterparts.

\section{Molecular Trees}

We have also analyzed the phylogenetic relationships of the mtDNA molecules and present two trees, one for the museum mtDNAs and the other for the modern mtDNAs (Fig. 8). Each tree is divisible into lineage segments, 22 for the museum tree and 21 for the modern tree; more than half of these segments are shared between the two trees and are designated by thick lines in Fig. 8. Moreover, the most frequent types in each population are derived from these shared lineages. So, the two trees are quite similar.

The outgroup used to root the modern and museum trees is $D$. californicus. For a subsection of the sequence compared among the $D$. panamintinus samples (positions 88-225), D. californicus has 14 additional substitutions and a 1-bp length difference at positions not variable among the $D$. panamintinus samples (Figs. 4 and 5). In addition, the pairwise differences lack the transition bias found within $D$. panamintinus (Table 4). Based on pairwise differences $D$. californicus is outside the $D$. panamintinus subspecies sampled and also shows effects of multiple hits based on its loss of a transition bias. ${ }^{2}$

In both molecular trees, the B clade and part of the $C$ clade appear to stem from clade $A$. In particular, both the B and C clades are clearly related to

\footnotetext{
${ }^{2}$ The population tree (Fig. 7) and the two molecular trees (Fig. 8) differ in the placement of the root. Whereas the root of the population tree falls on the $\mathrm{B}$ lineage, the roots of the modern and museum trees fall on $\mathrm{A}$ and $\mathrm{C}$ lineages. This discrepancy in root placement may reflect the relatively large distance between $D$. californicus and $D$. panamintinus. The lack of transition bias suggests that the observed difference between $D$. californicus and D. panamintinus (13-16\%) may be a severe underestimate and that multiple-hit phenomena may be significant, affecting the exact placement of the root based on the present character states in $D$. californicus
} 


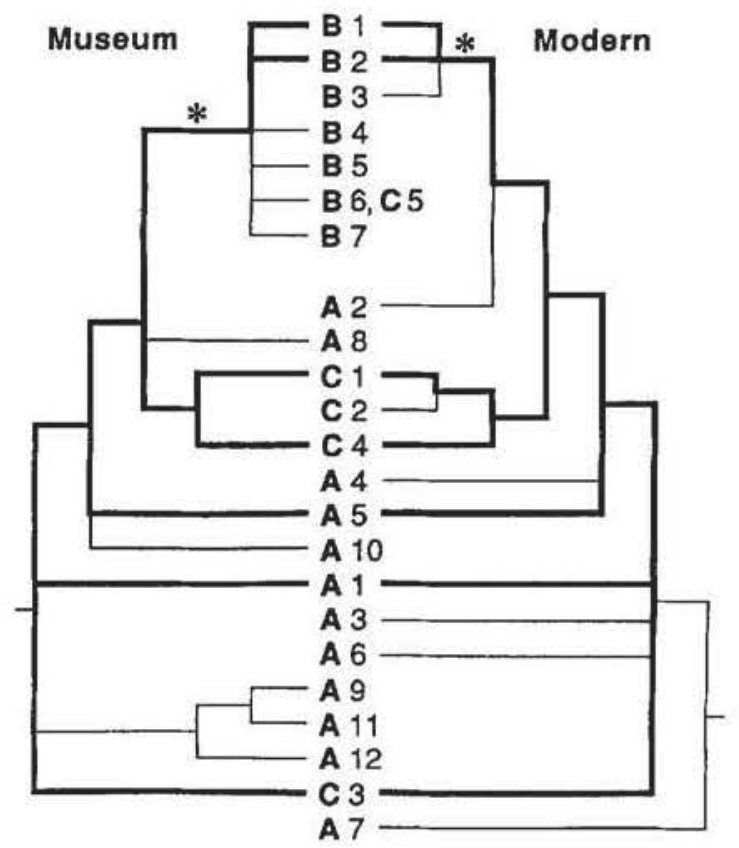

Fig. 8. Trees relating 23 types of miDNA from the Panamint kangaroo rats. Modern: Tree for 14 types of mtDNAs from $D$. panamintinus collected in 1988. Museum: Tree for 16 types of D. panamintinus mtDNA from museum specimens. Heavy lines represent lineages shared between the two temporal trees; lineages unique to a temporal sample are shown with thin lines. Asterisks mark the lineages where a chromosomal mutation leading to subspecies B occurred. The branching orders for the trees were in each case derived from 11 sites (among the 19 variable positions in Fig. 5) that are phylogenetically informative for relating the modern or museum $D$. panamintinus mtDNAs to one another. The sequence of $D$. californicus mtDNA (Fig. 5) was used to root the trees constructed. Each tree shown is a strict consensus one. That for museum specimens is the resultant of nine equally parsimonious trees, each of which requires $25 \mathrm{mu}-$ tations at 19 variable positions (consistency index $=0.84$ ). The consensus for modern specimens was derived from four trees, each of which requires 22 mutations at 16 variable positions (consistency index $=0.82$ ). The strict consensus tree for all 23 types of $D$. panamintinus mtDNA, derived from nine equally parsimonious solutions, each requiring 32 mutations at 19 variable positions, differs from the trees shown only in placing B4 outside the cluster of the remaining B types and abolishing the lineage uniting $\mathrm{A} 12$ with $\mathrm{A} 9$ plus $\mathrm{A} 11$.

the $\mathrm{A} 2$ and $\mathrm{A} 8$ lineages. In addition, the subspecies (C) with the fewest types and lowest diversity contains two very deep lineages, one leading to $\mathrm{C} 3$ and another to $\mathrm{C} 1, \mathrm{C} 2, \mathrm{C} 4$, and $\mathrm{C} 5$.

\section{Discussion}

\section{Distribution of Variation}

The finding that the TAS is conserved relative to the putative D-loop portion of the control region (Fig. 4 and Table 2) is consistent with a functional role for the TAS in termination of the D loop (Brown et al. 1986). An alternative explanation might in-
Table 6. Observed and expected pairs of individuals with identical mitochondrial types between temporal samples

\begin{tabular}{lllcr}
\hline & & & \multicolumn{2}{c}{$\begin{array}{c}\text { Number of identical } \\
\text { pairs }\end{array}$} \\
\cline { 3 - 5 } $\begin{array}{l}\text { Sub- } \\
\text { species }\end{array}$ & $\begin{array}{l}\text { Number } \\
\text { of pairs }^{n}\end{array}$ & $\begin{array}{l}\text { Probability } \\
\text { of identity }\end{array}$ & Expected & Observed \\
\hline A & 280 & $0.11-0.14$ & $31-39$ & 24 \\
B & 399 & $0.39-0.71$ & $156-283$ & 214 \\
C & 192 & $0.36-0.63$ & $69-121$ & 98 \\
\hline
\end{tabular}

" The total number of pairwise combinations between modern and museum samples

- The probability of identity is related to the diversity (h) in Table 5 and is equal to $1-h$. The range for $1-h$ reflects the $h$ values for each of the two temporal samples

- The range of expected identical pairs reflects the different diversities in each of the temporal samples

clude a higher mutational load for the triple-stranded region (Olivo et al. 1983). A comparison of evolutionary rates for these sequences to rates at silent positions of protein-coding genes should shed light on these alternative hypotheses.

The human control region has been shown to evolve at approximately five times the rate of the mitochondrial genome as a whole (Greenberg et al. 1983; Cann et al. 1987). Based on the nonrandom distribution of variation in the kangaroo rat sequence, we would not expect this segment of the Dipodomys control region to be evolving as fast as the entire human control region. We assume here that this 225 -bp sequence is diverging by $3.5 \%$ per million years, based on the assumption that only the rapidly evolving D-loop region is evolving at the high rate.

\section{Regional Continuity of Mitochondrial Genotypes}

\section{Lineage Maintenance}

For locality A, 10 of the 12 types are not shared between the 1911 and 1988 samples. Based on the genetic diversity at locality A $(\mathrm{h}=0.86-0.89)$, the probability that any two individuals chosen at random will have the same type is $0.11-0.14$ (Table 6). If the two temporal samples are drawn from the same population, then the number of pairs of individuals that share mitochondrial types between temporal samples is expected to be the product of the probability of identity and the total number of pairwise combinations between temporal samples. Therefore, of the 280 possible pairs at locality A, we expect 31-39 pairs to share types. The observed number (24) is not significantly different from that expected (Table 6). The apparent deficiency of shared genotypes between temporal samples at the A locality is thus consistent with a large population size and no change in genotype frequency with time, 
rather than, e.g., being attributable to migration events or population bottlenecks. For the B and C samples, the observed number of individuals that share mtDNA types is much higher than in A (Fig. 6 and Table 6). Again, the observed numbers of shared genotypes between temporal samples are not different from the expected numbers (Table 6).

At locality B we find the frequencies of mitochondrial types not to be statistically different in 1937 and 1988. Assuming a generation time of between 1 and 2 years, the effective population size over the 25-50 generations separating the two sample points would have to be very small (approximately 25-50 females) in order to detect a difference in genotype frequency between the museum and modern samples. Because the population sizes are expected to be orders of magnitude larger (Table 1), our finding that the frequencies of the mitochondrial types are invariant during this period is a direct observation completely consistent with the theory that the mitochondrial differences are neutral.

The locality representing the subspecies with the fewest individuals $(C)$ has the highest probability of experiencing changes in mitochondrial genotype frequencies over the time between samples. The mitochondrial genotype frequencies in Fig. 6 do not indicate any significant change in frequency of types, and the number of observed pairs with shared types is consistent with expectation (Table 6). ${ }^{3}$ It is noteworthy that if only the present-day population had been sampled, the observation of a very divergent lineage $(\mathrm{C} 3$, Fig. 8$)$ at locality $\mathrm{C}$ could have led to the suggestion that much of the variation in the $\mathrm{C}$ population is due to immigration events. Our diachronical approach shows that, at least for the 71 years sampled, the $C$ genotypes are present at the same frequency.

Temporal Stability of Population

and Molecular Trees

The relationships among the three populations based on mean pairwise differences (Fig. 7) are clearly the same for museum samples as for modern samples. The molecular trees (Fig. 8) make it evident that this congruency is the result of the persistence of major lineages between the new and old collections from all populations sampled.

Nevertheless, most of the A genotypes in the museum tree are different from those in the 1988 tree. This is probably the result of there being a great variety of closely related mtDNA types in the A population. Consistent with this view, the $\mathrm{A}$ individuals collected in 1911 are as diverse as those

\footnotetext{
${ }^{3}$ Nevertheless, we cannot exclude the possibility that both the B and $C$ populations have lost some variability over the period studied (Tables 5 and 6)
}

collected in 1988 (Table 5). Thus, the congruence indicates that our phylogenetic hypothesis is robust to temporal variation and to the presence or absence of specific lineages and that mtDNA diversity has been maintained within each of the three geographic regions sampled. ${ }^{4}$

\section{Geographic Distribution of Mitochondrial Genotypes}

\section{Geographic Substructure and Phylogeny}

There is a high degree of concordance for mtDNA types and geographic distributions, which implies little movement on a recent time scale. Only two out of the 106 individuals break the association of each mtDNA type with a specific population. However, phylogenetically, this is not as true. The nearest relative of a randomly picked type from the A or $C$ localities is not always another $A$ or $C$ type, respectively (Fig. 8). Of the three populations the most phylogenetically distinct is B, where the nearest relative of any B type is always another B type.

That the $B$ samples are monophyletic with respect to the $A$ and $C$ lineages is supported by an observed karyological difference among these subspecies. The $B$ subspecies is unique in having a one-armed chromosome in place of a two-armed version present in the other four subspecies and in $D$. californicus (Dingman et al. 1971; Stock 1974), suggesting that the B karyotype is derived. If this chromosomal change were due to a dramatic event, such as a pericentric inversion, which could have severe meiotic consequences, a population bottleneck may have been required for this karyotype to become fixed. Although the observed karyological difference could be due to an inversion, the one-armed $\mathrm{B}$ chromosome is also smaller than its counterpart in A (Stock 1974), suggesting that this may represent the meiotically mild loss of a heterochromatic arm.

The mean pairwise differences and estimates of diversity within localities A and B (Table 5) correlate with estimates of population size based on geographic range (Table 1). By contrast, the sample of subspecies C, with an expected population size much smaller than $B$, has as much diversity as the $B$ sample (Table 5). However, the range of pairwise differences in $\mathrm{C}$ (from one to eight substitutions) is much larger than for B (one to three substitutions). This increased range may reflect immigration events from the large neighboring A population, which is geographically close to the $\mathrm{C}$ population, thereby inflating the estimate of C's population size. (Removal of the two low-frequency divergent lineages,

\footnotetext{
${ }^{4}$ Low-frequency lineages shared by populations (C5, B6) also underscore the importance of large sample sizes for valid systematic interpretations
} 


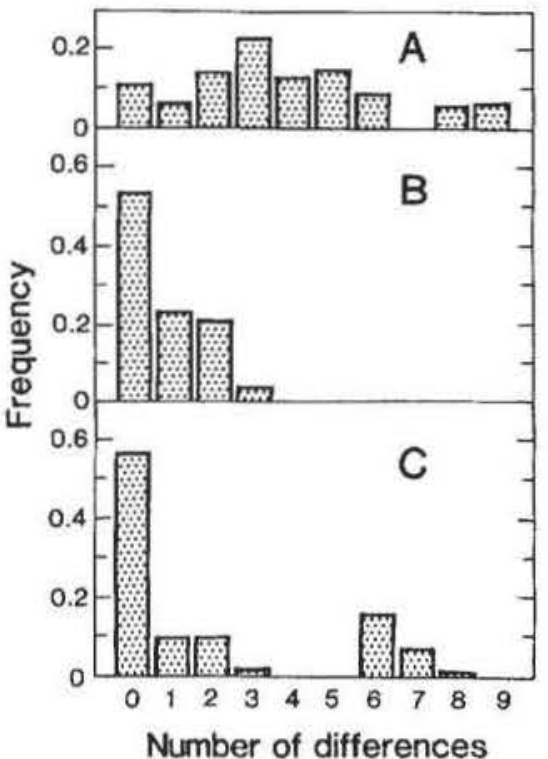

Fig. 9. Frequencies of the number of differences between mitochondrial sequences for all possible pairs of animals within each of the three localities. The total number of pairs is 561 for A, 780 for B, and 496 for C.

$\mathrm{C} 3$ and $\mathrm{C} 5$, reduces the mean pairwise difference dramatically.) If so, further sampling may reveal the presence of $\mathrm{C} 3$ and $\mathrm{C} 5$ in subspecies A. Shared lineages are likely to be a remnant of a time when these subspecies had contiguous geographic ranges. The vegetational history indicates that their ranges were contiguous as recently as 13,000 years ago (McCarten and Van Devender 1988), a time much shorter than the times to common ancestry for all three subspecies.

The A samples are clearly derived from a more diverse population than either the $\mathrm{B}$ or $\mathrm{C}$ samples, indicating a large effective population size for $\mathrm{A}$ relative to the latter two populations. That it may have served as a donor population for the other less diverse subspecies is supported by the rooted trees (Fig. 8) and consistent with the biogeography of the northern Mojave region and the heermanni group of kangaroo rats, to which $D$. panamintinus belongs. The diversity observed at locality $A$ further suggests that, although kangaroo rats are highly sedentary (Jones 1987, 1989), this does not preclude the existence of high levels of variation within localities. A more complete survey of the temporal and spatial mitochondrial variation in D. panamintinus should contribute greatly to an understanding of the population dynamics and evolution of this species as well as the faunal history of the Mojave region.

\section{Geographic Substructure and Pairwise Distances}

Another way to evaluate the evolutionary history of these subspecies is to compare the distribution of pairwise distances within each locality sampled
(Fig. 9). The distribution in population $\mathrm{A}$ differs from that found in B and C in two important ways. First, it has a low frequency in the zero difference class. By contrast, both B and C are dominated by the zero difference class, as a result of having a large proportion of individuals of a single genotype. Second, the genotypes found in the A population are, in general, more distantly related to one another (Table 5 and Fig. 8). Both of the above observations concerning population $A$ are consistent with its having a larger long-term effective population size than B or C (Avise et al. 1988). Large population sizes are expected to increase diversity and reduce the frequency of the zero class by increasing the probability of lineage survival over time. The increased probability of lineage survival would be expected to increase the frequency of more divergent classes as seen in the A population.

Morphological differences among the three subspecies are subtle, and, although mean values differ, there is substantial overlap in the distributions of these differences. A review of the original descriptions (Merriam 1894; Grinnell 1918; Hall 1946) and subsequent taxonomic reevaluations (Grinnell 1922; Hall 1946, 1981) indicate that these three subspecies differ in the following manner: On average subspecies B is the largest (head + body + tail), C is intermediate, and $\mathrm{A}$ is the smallest. The auditory bullae of $B$ are the most flattened, of $A$ the least flattened, and those of $\mathrm{C}$ again intermediate. Within subspecies geographic variation is to be expected. The published descriptions are from specimens at each of the three type localities. The mtDNAs from subspecies B and C are also from the type localities, whereas our A sample is $51 \mathrm{~km}$ away from the type locality for D. p. mohavensis.

\section{Authenticity of Sequences from Museum Skins}

It has been shown before that PCR can amplify DNA sequences from museum specimens (Pääbo and Wilson 1988; Thomas et al. 1989) as well as from archaeological remains (Pääbo et al. 1988; Pääbo 1989) and that direct sequencing of the amplification products is essential for correct sequences to be determined (Pääbo and Wilson 1988), as bacterial cloning may introduce errors due to misrepair of lesions present in old DNA. The present study expands these results and demonstrates the routine nature of amplification and direct sequencing of DNA from museum specimens, in that the extraction, amplification, and sequencing of 43 out of 49 museum specimens were accomplished. ${ }^{5}$

\footnotetext{
'Six museum specimens of population C (D. p. panamintinus) had to be excluded from analysis because more than one mitochondrial sequence was visualized in the sequencing gel, although
} 
The authenticity of the sequences obtained is shown by the fact that the sequences from many of the skins dried in 1911,1917, and 1937 are identical to the sequences determined in modern specimens or fall into the appropriate clade (Figs. 7 and 8). If the methods employed here had introduced errors, the sequences derived for museum specimens would not be identical to those from modern specimens. Nor would the types of changes (transitions) and distribution of changes follow expected patterns. Sequence differences among museum specimens are distributed along the mitochondrial molecule in accordance with the functional constraints model (Fig. 2 and Table 2), and transitions dominate among museum specimens. It is thus clear that museum specimens represent a vast new source of material for studies at the DNA sequence level-a resource that includes approximately one million mammal specimens in North American collections alone (Yates et al. 1987).

Acknowledgments. We thank E.M. Prager for numerous discussions and extensive computational and editorial assistance and $M$. Stoneking, F. Allendorf, and M. Slatkin for comments on the manuscript. This work received support from grants to A.C.W. from the National Science Foundation and the National Institutes of Health, from a National Institutes of Health postdoctoral fellowship to W.K.T., and from a National Science Foundation graduate fellowship to F.X.V. We wish to thank the curators of mammals at the MVZ, J.L. Patton and W.Z. Lidicker, for helpful discussions and encouraging the use of specimens in their care.

\section{References}

Avise JC, Ball RM, Amold J (1988) Current versus historical population sizes in vertebrate species with high gene flow: a comparison based on mitochondrial DNA lineages and inbreeding theory for neutral mutations. Mol Biol Evol 5:331344

Bibb MJ, Van Etten RA, Wright CT, Walberg MW, Clayton DA (1981) Sequence and gene organization of mouse mitochondrial DNA. Cell 26:167-180

Brown GG, Gadaleta G, Pepe G, Saccone C, Sbisà E (1986) Structural conservation and variation in the D-loop-containing region of vertebrate mitochondrial DNA. J Mol Biol 192: 503-511

there were no products detected in control amplifications prepared in parallel with these samples. In all six cases, one of the sequences was identical to that determined for another closely related species, $D$. heermanni. It should be noted that $D$. panamintimus and $D$. heermanni have nonoverlapping ranges (Hall 1981) and are karyotypically distinct (Stock 1974) although genetically similar in other respects (Johnson and Selander 1971; Patton et al, 1976). Two explanations could account for the occurrence of $D$. heermanni mtDNA in the $D$. panamintimus extracts. Either the museum specimens were contaminated at some point during their preparation and storage by $D$. heermanni tissue, or this represents a case of heteroplasmy due to introgression and paternal contribution.
Cabot EL, Beckenbach AT (1989) Simultaneous editing of multiple nucleic acid and protein sequences with ESEE. Comput Appl Biosci 5:233-234

Cann RL, Stoneking M, Wilson AC (1987) Mitochondrial DNA and human evolution. Nature 325:31-36

Dingman RE, Davis RJ, Hunsaker D (1971) Karyotypes of the Panamint kangaroo rat (Dipodomys panamintinus (Merriam)). Experientia 27:1491-1492

Greenberg BD, Newbold JE, Sugino A (1983) Intraspecific nucleotide sequence variability surrounding the origin of replication in human mitochondrial DNA. Gene 21:33-49

Grinnell J (1918) Six new mammals from the Mohave Desert and Inyo regions of California. Univ Calif Publ Zool 17:423430

Grinnell J (1922) A geographical study of the kangaroo rats of California. Univ Calif Publ Zool 24:1-124

Hall ER (1946) Mammals of Nevada. University of California Press, Berkeley CA

Hall ER (1981) The mammals of North America, ed 2. John Wiley and Sons, New York, p 573

Harrison RG (1988) Animal mitochondrial DNA as a genetic marker in population and evolutionary biology. Trends Ecol Evol 4:6-11

Johnson WE, Selander RK (1971) Protein variation and systematics in kangaroo rats (genus Dipodomys). Syst Zool 20: $377-405$

Jones WT (1987) Dispersal patterns in kangaroo rats (Dipodomys spectabilis). In: Chepko-Sade BD, Harpin ZT (eds) Mammalian dispersal patterns: the effects of social structure on population genetics. University of Chicago Press, Chicago, pp 119-127

Jones WT (1989) Dispersal distance and the range of nightly movements in Merriam's kangaroo rat. J Mammal 70:27-34

Kocher TD, Thomas WK, Meyer A, Edwards SV, Pääbo S, Villablanca FX, Wilson AC (1989) Dynamics of mtDNA evolution in animals: amplification and sequencing with conserved primers. Proc Natl Acad Sci USA 86:6196-6200

McCarten N, Van Devender TR (1988) Late Wisconsin vegetation of robber's roost in the western Mojave Desert, California. Madroño 35:226-237

Merriam CH (1894) Preliminary descriptions of eleven new kangaroo rats of the genera Dipodomys and Perodipus. Proc Biol Soc Wash 9:109-116

Nei M, Tajima F (1981) DNA polymorphism detectable by restriction endonucleases. Genetics 97:145-163

Olivo PD, Van de Walle MJ, Laipis PJ, Hauswirth WW (1983) Nucleotide sequence evidence for rapid genotypic shifts in the bovine mitochondrial DNA D-loop. Nature 306:400-402

PääboS (1989) Ancient DNA: extraction, characterization, molecular cloning, and enzymatic amplification. Proc Natl Acad Sci USA 86:1939-1943

Pääbo S (1990) Amplifying ancient DNA. In: Innis M, Gelfand D, Sninsky J, White T (eds) PCR protocols: a guide to methods and applications. Academic Press, Orlando FL, pp 159-166

Pääbo S, Wilson AC (1988) Polymerase chain reaction reveals cloning artefacts. Nature 334:387-388

Pääbo S, Gifford JA, Wilson AC (1988) Mitochondrial DNA sequences from a 7000-year old brain. Nucleic Acids Res 16: 9775-9787

Pääbo S, Higuchi RG, Wilson AC (1989) Ancient DNA and the polymerase chain reaction. The emerging field of molecular archaeology. J Biol Chem 264:9709-9712

Patton JL, MacArthur H, Yang SY (1976) Systematic relationships of the four-toed populations of Dipodomys heermanni. J Mammal 57:159-163

Roe BA, Ma D-P, Wilson RK, Wong JF-H (1985) The complete nucleotide sequence of the Xenopus laevis mitochondrial genome. J Biol Chem 260:9759-9774 
Saccone C, Attimonelli M, Sbisà E (1985) Primary and higher order structural analysis of animal mitochondrial DNA. In: Quagliariello E, Slater EC, Palmieri F, Saccone C, Kroon AM (eds) Achievements and perspectives of mitochondrial research, vol Il. Elsevier, Amsterdam, pp 37-47

Stock AD (1974) Chromosome evolution in the genus Dipodomys and its taxonomic and phylogenetic implications. J Mammal 55:505-526

Swofford DL (1989) PAUP: phylogenetic analysis using parsimony, version 3.0b. Illinois Natural History Survey, Champaign IL

Thomas RH, Schaffner W, Wilson AC, Pääbo S (1989) DNA phylogeny of the extinct marsupial wolf. Nature 340:465-467

White TJ, Arnheim N, Erlich HA (1989) The polymerase chain reaction. Trends Genet 5:185-189

Wilson AC, Cann RL, Carr SM, George M, Gyllensten UB, HelmBychowski KM, Higuchi RG, Palumbi SR, Prager EM, Sage RD, Stoneking M (1985) Mitochondrial DNA and two perspectives on evolutionary genetics. Biol J Linn Soc 26:375400

Yates TL, Barber WR, Armstrong DM (1987) Survey of North American collections of recent mammais. J Mammal [Suppl] 68

\section{Appendix}

The individual animals yielding each of the 23 types of mtDNA are listed below according to MVZ catalogue numbers. Museum skins from all the individuals listed are available at the MVZ. Numbers preceded by asterisks refer to modern specimens (i.e., those collected in 1988) with tissues preserved in the MVZ frozen collection.

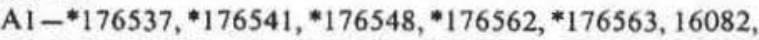
$16094,16095,16112$; A2 - *176540, *176542, *176543,*176555; A3-*176538,*176544,*176556,*176561; A4-*176545, $\bullet 176546, * 176564 ;$ A5 - *176536,*176551, 16085, 16086; A6*176558; A7-*176557; A8-16080; A9-16078, 16096; A1016087,$16089 ; \mathrm{A} 11-16084 ;$ A $12-16126,16127$.

B1 -*176579, *176583-176594,*176596-176598, 80023$80025,80027,80030,80031,80033,80034,80037,80041,80042$, 80044,80045 ; B2-*176580, *176581, 80026, 80029, 80040; B3-*176595; B4-80035, 80036; B5-80032; B6-80039; B780038.

$\mathrm{Cl}-* 176566-176570, * 176572, * 176573, * 176575, * 176576$, *176578,*176602-176606, *176609-176612, 26854, 26856, 26857, 26863, 26866; C2-*176571, *176607; C3-*176574, $* 176599,26865 ;$ C4-*176601, 26872; CS-26849.

The six museum specimens of $D$. p. panamintinus, that yielded two sequences (see footnote 5) are MVZ numbers 26846 , $26848,26852,26853,26859$, and 26861. 